\title{
Halofuginone mediated protection against radiation-induced leg contracture
}

\author{
HISANARI ISHII ${ }^{1}$, RAJANI CHOUDHURI ${ }^{1}$, ASKALE MATHIAS ${ }^{1}$, ANASTASIA L. SOWERS ${ }^{1}$, \\ KATHLEEN C. FLANDERS ${ }^{2}$, JOHN A. COOK $^{1}$ and JAMES B. MITCHELL ${ }^{1}$ \\ ${ }^{1}$ Radiation Biology Branch and ${ }^{2}$ Laboratory of Cell Regulation and Carcinogenesis, \\ Center for Cancer Research, National Cancer Institute, Bethesda, MD 20892-1002, USA
}

Received March 16, 2009; Accepted May 19, 2009

DOI: 10.3892/ijo_00000342

\begin{abstract}
Fibrosis of normal tissues often accompanies radiation treatment of cancer. Activation of the transforming growth factor- $\beta$ (TGF- $\beta$ ) signaling pathway is thought to play a major role in radiation-induced fibrosis and has prompted the development and assessment of low molecular weight inhibitors of the pathway. Previous studies with halofuginone have shown it to inhibit TGF- 3 signaling in vitro and protect mice from radiation-induced leg contraction (a model for soft tissue fibrosis). The current study confirms these findings for $\mathrm{HaCaT}$ cells stimulated with exogenous TGF- $\beta$ treatment. Reducing the halifuginone treatment from 7 days/week (used previously) to 5 days/week post-radiation exposure provided significant protection against radiation-induced leg contraction in mice 3 and 4 months post-radiation treatment. Halofuginone treatment was shown to attenuate TGF- $\beta$ signaling molecules taken from irradiated skin including TGF-ßRII, pSmad3, Smad7, and TSP1. The latter, TSP1, a co-activator of TGF- 3 may serve as a suitable biomarker for monitoring the efficacy of halofuginone should it be evaluated in a clinical setting for protection against radiation-induced fibrosis.
\end{abstract}

\section{Introduction}

Soft tissue fibrosis often occurs in normal tissues following radiation treatment (1-3). Dependent on the severity of the fibrosis, the quality of life for patients treated with radiation can be impaired, thereby necessitating a need for interventions that might protect against and/or mitigate this toxicity. Ionizing radiation can activate the TGF- $\beta$ pathway $(4,5)$ and there is considerable evidence that suggests that activation of the TGF- $\beta$ pathway is a major contributor to radiation-induced

Correspondence to: Dr James B. Mitchell, Radiation Biology Branch, National Cancer Institute, Bldg. 10, Room B3-B69, Bethesda, MD 20892-1002, USA

E-mail: jbm@helix.nih.gov

Key words: fibrosis, TGF- $\beta$, radiation, halofuginone, protection fibrosis (6-8). Radiation activates TGF- $\beta$ from its latent form $(4,5)$. Once activated, a series of signal transduction reactions occur starting with binding of TGF- $\beta$ to the trans-membrane TGF- $\beta$ Type II receptor. This is followed by a recruitment of the TGF- $\beta$ Type I receptor and thereafter the formation of Type II/Type I heterodimer which is phosphorylated. This activated complex serves to phosphorylate and activate downstream signaling proteins such as Smad2 and 3, which bind with Smad4 for transport to the nucleus and initiation of transcription that leads to activation and/or repression of gene expression (9). Thus, members of the TGF- $\beta$ signaling pathway represent potential molecular targets for inhibition, which upon inhibition might attenuate or even prevent radiationinduced fibrosis. Targeting the TGF- $\beta$ signaling pathway has already shown efficacy in pre-clinical models where radiationinduced fibrosis is decreased (10-13).

Halofuginone is a plant derived alkaloid that exhibits antifibrotic activity, and inhibition of type I collagen synthesis (14). Halofuginone has been shown to protect against radiationinduced soft tissue fibrosis by virtue of inhibiting various members of the TGF- $\beta$ signaling pathway (15). While this study utilized halofuginone in an in vivo model for radiationinduced fibrosis, the mechanistic studies evaluating inhibition of TGF- $\beta$ signaling members were conducted using in vitro systems. The present study was designed to extend upon these observations and to specifically determine whether halofuginone treatment would inhibit TGF- $\beta$ signaling pathway targets in vivo. The results of the study clearly demonstrate that halofuginone inhibits members of the TGF- $\beta$ signaling pathway that are activated by radiation treatment in vivo and thus provides a rationale for clinical evaluation of halofuginone to attenuate radiation-induced soft tissue fibrosis.

\section{Materials and methods}

Reagents. Halofuginone (dl-trans-7-bromo-6-chloro-3-[3-(3hydroxy-2piperidyl)acetonyl]-4(3H)-quinazolinone hydrobromide) was obtained from Collgard Biopharmaceuticals, Herzliya, Israel. Stock solutions of $1-2 \mathrm{mg} / \mathrm{ml}$ were prepared by dissolving crystalline halofuginone in a lactic acid buffer, $0.44 \mathrm{M}, \mathrm{pH} 4.3$, and stored at $4^{\circ} \mathrm{C}$ where it is stable for at least 4 months. Working solutions for injection of halofuginone ( 1 or $5 \mu \mathrm{g} / 100 \mu \mathrm{l}$ ) were made each day by diluting the stock halofuginone with $0.9 \% \mathrm{NaCl}$. The working solution was 
used within $1 \mathrm{~h}$ of preparation. Mouse monoclonal antithrombospondin-1 (TSP1) antibody was purchased from Thermo Scientific (Fremont, CA). Rabbit polyclonal antiSmad2 antibody (Ser465/467) and mouse actin monoclonal antibody was purchased from Millipore Corp. (Temecula, CA). Rabbit anti-phospho Smad2 polyclonal antibody was purchased from Zymed Invitrogen Corp. (Carlsbad, CA). Rabbit monoclonal anti-Smad3 and anti-phosphorylated Smad3 antibody was purchased from Epitomics (Burlingame, CA). Rabbit polyclonal anti-Smad7 antibody (C-term) was purchased from Zymed Laboratories Inc. (South San Francisco, CA). Mouse polyclonal anti-TGF- 3 type II receptor (TRII) antibody and mouse Smad7 polyclonal antibody was purchased from Novus Biological, Inc. (Littleton, CO). Human TGF-3 was purchased from R\&D Systems, Inc. (Minneapolis, MN).

Cell studies. Transformed human keratinocyte cell line (HaCaT) was obtained from Dr N.E. Fusenig, (German Cancer Research Center, Heidelberg, Germany) (16). HaCaT cells were maintained in DMEM medium supplemented with $5 \%$ fetal calf serum and antibiotics. Cells were grown to $\sim 80 \%$ confluence, rinsed with PBS, and switched to medium containing $0.2 \%$ serum and incubated overnight. Cells were then treated with halofuginone $(250 \mathrm{nM}$, final concentration) for a total of $24 \mathrm{~h}$; activated TGF- $3(2 \mathrm{ng} / \mathrm{ml})$ was added the last $6 \mathrm{~h}$. Following treatment, cells were rinsed with PBS, lysed with RIPA lysis buffer (Santa Cruz Biotechnology) in the presence of sodium orthovanadate and protease inhibitors (Sigma Aldrich). Following $30 \mathrm{~min}$ of incubation on ice, the samples were centrifuged at $14,000 \mathrm{x} \mathrm{g}$, and the supernatant protein concentration was determined by DC Protein Assay (Bio-Rad). Protein samples were stored at $-70^{\circ} \mathrm{C}$ for subsequent Western blot analysis. This experiment was replicated twice.

Animal studies. Female $\mathrm{C} 3 \mathrm{H} / \mathrm{Hen}$ mice, bred in the National Cancer Institute Animal Production Area (Frederick, MD), were used for this study. The mice were 8-10 weeks of age at the time of experimentation and weighed between 20-30 g. All experiments were carried out under the aegis of a protocol approved by the National Cancer Institute Animal Care and Use Committee and were in compliance with the Guide for the Care and Use of Laboratory Animal Resource, National Research Council. Selective irradiation of the right leg was accomplished by placing each un-anesthetized animal into a specially built Lucite jig that immobilized the animal and facilitated ease of extension of the right hind leg into the radiation field. Lead shields designed as a part of the Lucite jigs assured that only the right hind limb of the immobilized animal was irradiated. A single radiation dose of 35 Gy was delivered to the right hind leg of the animal by a Therapax DXT300 X-ray irradiator (Pantak, Inc., East Haven, CT) using $2.0-\mathrm{mm} \mathrm{Al}$ filtration ( $300 \mathrm{kV}$ peak) at a dose rate of $1.8 \mathrm{~Gy} / \mathrm{min}$. Immediately after irradiation, animals were removed from the Lucite jig and housed (4 animals/cage) in a climate and light/dark-controlled environment and allowed free access to food and water. Halofuginone treatment started immediately after the radiation exposure and daily injections (Mon-Fri) continued up to 4 months post-radiation. Each animal received 1 or $5 \mu \mathrm{g} /$ mouse/day halofuginone as an intraperitoneal (i.p.) injection (injection volume was $100 \mu \mathrm{l}$ ).
Eight animals were in each of the 1 and $5 \mu \mathrm{g} / \mathrm{mouse} /$ day treatment groups and 8 animals were in the control vehicle only group. Control animals received vehicle solution only. Fibrosis as measured by leg contraction was assessed as previously described $(15,17)$. Briefly, a Lucite jig was made such that the body of the animal could be easily positioned within it and extension of the leg could be measured by referring to an inlaid ruler within the base of the jig. The degree of contraction was recorded after extension of the irradiated right hind leg and compared with the extended length of the un-irradiated contra-lateral hind leg. The length of leg could easily be measured with an accuracy of $1 \pm 0.5 \mathrm{~mm}$. The length of the irradiated leg is expressed as the percent of the control un-irradiated leg.

Some experiments involved local irradiation to the skin of the flank region. In the same way as the leg irradiation, animals (without anesthetics) were placed in customized Lucite jigs that allow for immobilization and selective irradiation of the skin of the flank. Special clamps held the skin without decreasing blood flow to the treatment area as determined previously by laser Doppler studies. A single radiation dose of $35 \mathrm{~Gy}$ was delivered to the right flank of the animal. Special care was taken to avoid irradiation of other body parts by using lead shields specifically designed as a part of the jigs. Four animals were in the $5 \mu \mathrm{g} /$ mouse/day treatment group and four animals were in the control vehicle only group. Halofuginone injections ( $5 \mu \mathrm{g} / \mathrm{mouse} /$ day) were initiated immediately after irradiation followed by daily injections. One of the animals in each group was euthanized and the skin was removed at 24, 48, 72, and $96 \mathrm{~h}$ post-radiation. After removal the skin samples were snap-frozen in liquid nitrogen and stored at $-70^{\circ} \mathrm{C}$ for Western blotting. This experiment was replicated twice.

Western blot analysis. Protein samples of equal amounts were subjected to PAGE on 4-20\% Tris-glycine acrylamide gels (Novex-Invitrogen). Following transfer to nitrocellulose by iBlot Gel Transfer Device (Novex-Invitrogen), samples were probed with primary antibodies diluted 1:200-2000, followed by the appropriate secondary antibody diluted to 1:2000 and visualized by chemiluminescence (Perkin-Elmer). To confirm equal protein loading and transfer, membranes were stripped by ReBlot Plus (Chemicon) and reprobed using anti-actin antibody.

Statistical analyses. Mean \pm SE was calculated and significance was analyzed using a two-tailed Student's t-test.

\section{Results}

Inhibition of the TGF- $\beta$ signaling pathway by halofuginone: in vitro studies. To determine the effects of halofuginone on the TGF- $\beta$ signaling pathway, HaCaT cells were pretreated with or without halofuginone $(250 \mathrm{nM})$ for $24 \mathrm{~h}$. TGF- $\beta$ was added to the cells for the last $6 \mathrm{~h}$ to stimulate the TGF- $\beta$ pathway. A variety of TGF- $\beta$ signaling molecules were evaluated by Western blot analysis as shown in Fig. 1. Halofuginone treatment alone resulted in decreases in TGF-ßRII, TSP1, pSmad3, and total Smad3 protein levels compared to untreated controls. Smad7 levels increased 


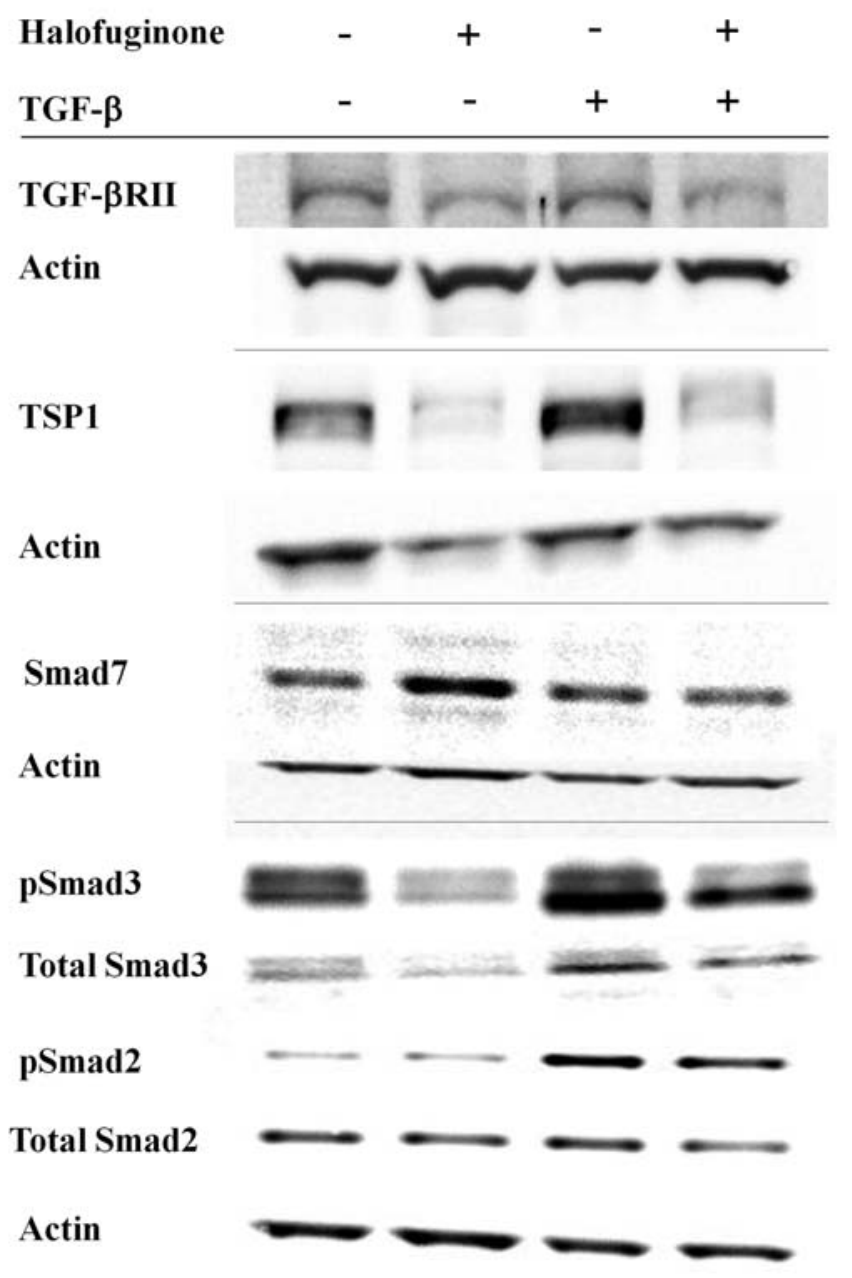

Figure 1. Western blot analysis of proteins extracted from HaCaT cells treated with or without a $24-\mathrm{h}$ pretreatment of $250 \mathrm{nM}$ halofuginone; TGF- $\beta$ $(2 \mathrm{ng} / \mathrm{ml})$ was added the last $6 \mathrm{~h}$ of the halofuginone treatment.

marginally following halofuginone treatment. No change in either pSmad2 or total Smad2 levels after halofuginone treatment was observed.

Treatment of cells with TGF- $\beta$ alone resulted in increases in both pSmad 2 and pSmad3. TSP1 levels were also elevated following TGF- $\beta$ treatment; whereas, TGF-BRII levels were essentially unchanged. Stimulation of TGF- $\beta$ signaling molecules was attenuated by combination treatment with halofuginone and TGF- $\beta$, with pSmad $3, \mathrm{pSmad} 2$, and TSP1 levels decreased compared to TGF- $\beta$ treatment alone. Smad7 and TGF-ßRII levels were unchanged. Collectively, these studies show that halofuginone treatment alone exerts effects on TGF- $\beta$ signaling molecules by decreasing activation and/or levels of key proteins in the pathway. When the TGF- 3 pathway was stimulated by TGF- $\beta$, halofuginone suppressed the activation/levels of several of the key pathway members.

Halifuginone protects against radiation-induced leg contracture. Our previous studies with halifuginone and radiation-induced leg contracture utilized daily dosing of halofuginone post-radiation treatment (15). In the present study, we sought to determine if less dosing of halofuginone would result in protection. Five daily doses of halofuginone

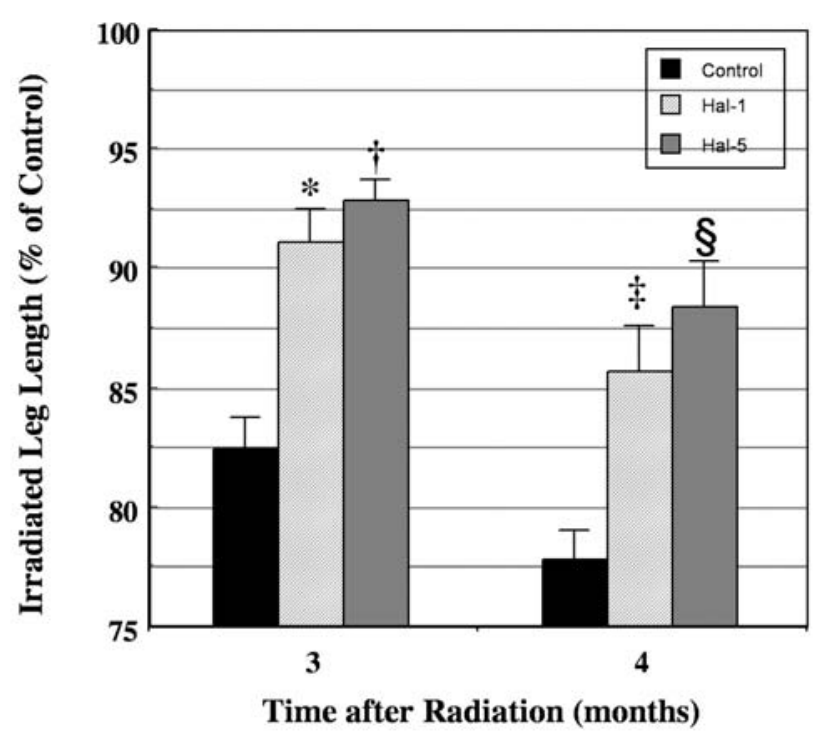

Figure 2. Radiation-induced leg contraction at 3 and 4 months post-radiation treatment without or with halofuginone treatment (hashed column, $1 \mu \mathrm{g} /$ mouse/day; gray column, $5 \mu \mathrm{g} / \mathrm{mouse} /$ day). Compared to radiation only controls, both doses of halofuginone provided protection at 3 months $\left({ }^{*} \mathrm{p}<0.004 ;{ }^{\dagger} \mathrm{p}<0.00002\right)$ and 4 months $\left({ }^{*} \mathrm{p}<0.002 ;{ }^{\S} \mathrm{p}<0.0002\right)$ post-radiation treatment.

(instead of 7) were given per week for periods extending to 4 months. This protocol more closely resembles how halofuginone might be delivered in a clinical setting. Exposure of control legs to $35 \mathrm{~Gy}$ resulted in leg contracture of $\sim 18 \%$ and $23 \%$ when evaluated at 3 and 4 months post-radiation, respectively as shown in Fig. 2. For this radiation dose, the contraction observed was consistent with our previous studies (15) and other published studies (17). Halofuginone treatment at 1 and $5 \mu \mathrm{g} / \mathrm{mouse}$ resulted in significant protection against radiation-induced leg contraction when evaluated at both 3 and 4 months post-radiation treatment.

Inhibition of the TGF- $\beta$ signaling pathway by halofuginone: in vivo. Radiation has been shown to activate the TGF- $\beta$ pathway in various normal tissues in vivo $(4,5)$. We next determined if halofuginone treatment could suppress radiationinduced activation of the TGF- $\beta$ pathway by collecting skin samples from animals exposed to radiation only and radiation plus daily halofuginone treatment for 4 consecutive days post-radiation. Radiation treatment alone resulted in increases in pSmad3, TSP1, Smad7, and TGFßRII as shown in Fig. 3. pSmad3 levels peaked between 48-72 h post-radiation where they were higher than control levels. pSmad3 levels slowly declined by $96 \mathrm{~h}$; however, at $96 \mathrm{~h}$ the levels were still higher than control values. pSmad2 levels were unchanged over the time course (data not shown). Radiation treatment induced TSP1 levels with maximum induction at $24 \mathrm{~h}$ post-radiation ( 2-fold) followed by a gradual decline approaching control levels by 72-96 h. Likewise, TGFßRII levels were elevated at $24 \mathrm{~h}$ following radiation treatment and remained elevated to 96 h. Smad7 levels were also elevated by $\sim 25 \%$ over control values over the 24-96 h time course. Daily halofuginone treatment of irradiated animals suppressed radiation-induced activation of TSP1, pSmad3, Smad7, and TGFßRII. 


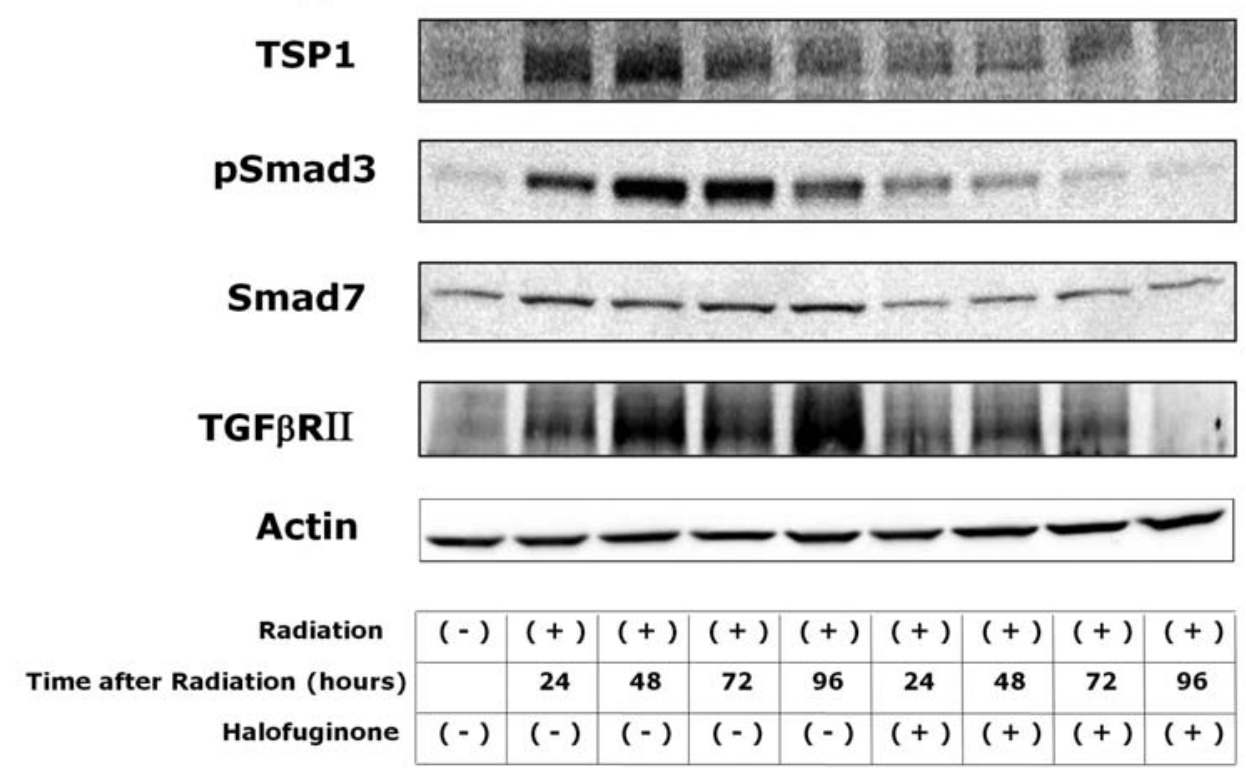

Figure 3. Western blot analysis of proteins extracted from mouse skin exposed to a single radiation dose of 35 Gy without or with daily i.p. treatments of halofuginone ( $5 \mu \mathrm{g} / \mathrm{mouse} /$ day) for 4 days. The first dose of halofuginone was given immediately after the radiation exposure.

\section{Discussion}

Radiation treatment is known to activate TGF- $\beta$ followed by activation of members of the TGF- $\beta$ signaling pathway $(4,5,9)$. Exogenously applied TGF- $\beta$ will also activate the TGF- $\beta$ signaling pathway and was used to evaluate whether halofuginone would be effective in attenuating TGF- $\beta$ pathway activation. Treatment of HaCaT cells with exogenous TGF- $\beta$ resulted in activation of key members of the TGF- $\beta$ signaling pathway, in particular pSmad2 and pSmad3, consistent with our previous studies (15). TGF- $\beta$ treatment also induced TSP1 levels in HaCaT cells. Only modest induction was observed for TGF-ßRII. In contrast, treatment of HaCaT cells with halofuginone treatment alone lowered TSP1, pSmad3 and total Smad3 levels. Pretreatment of cells with halofuginone before addition of TGF- $\beta$ attenuated activation for $\mathrm{pSmad} 3$, total Smad3, and TSP1, suggesting that halofuginone was effective in blunting activation of the TGF- $B$ pathway. The in vitro studies revealed two characteristics of halofuginone that had not been previously observed. First, halofuginone treatment had been previously shown to enhance production of Smad7 RNA (15); however, protein levels had not been evaluated. The current study demonstrates that halofuginone treatment did not increase Smad7 protein levels in HaCaT cells treated with TGF- 3 . Second, halofuginone treatment alone or in combination with TGF- $\beta$ activation suppressed levels of TSP1. TSP1 is a homeotrimeric cellular matrix protein and is a co-activator of TGF- $\beta$ along with the latencyassociated peptide (18). Blocking TGF- $\beta$ signaling upstream at the TGF- $\beta$ activation step would explain how other downstream members of the TGF- $\beta$ pathway would be effected by halofuginone treatment. The mechanism of TSP1 suppression by halofuginone is not known.

In agreement with our previous study, halofuginone treatment post-radiation provided significant protection against radiation-induced leg shortening even though halofuginone was administered daily (Monday through Friday) instead of seven days per week for four months. The extent of protection was slightly less in the present study for both halofuginone doses compared to our previous study. For example, the irradiated leg length (\% of control) 4 months after radiation exposure was 85.5 and $88 \%$ for 1 and $5 \mu \mathrm{M}$ halofuginone concentrations, respectively, compared to 97 and $95 \%$ for 1 and $5 \mu \mathrm{M}$ halofuginone concentrations in our previous study. Despite the fact that the same animal strain was used and the radiation/drug conditions were the same, administering halofuginone 7 days per week yielded somewhat better results. The significance of this observation is unclear; however, missing halofuginone doses over the weekends might have allowed for transient recovery of TGF- $\beta$ signaling followed partial initiation of pro-fibrotic reactions. Elevated levels of TGF- $\beta$ in normal tissues and blood have been observed weeks to months following radiation treatment $(19,20)$, which is consistent with the notion that radiation-induced fibrosis is a chronic ongoing process. Further studies will be required to determine if TGF- $\beta$ signaling transiently recovers following 5 daily treatments of halofuginone in irradiated tissues.

Using a halofuginone dosing schedule that provided protection against radiation-induced soft tissue fibrosis, provided the framework to determine if halofuginone given daily after radiation would attenuate the TGF- $\beta$ signaling pathway in vivo. Radiation treatment alone to the skin did in fact activate several members of the TGF- $\beta$ signaling pathway, including TGF-BRII, pSmad3, Smad7, and TSP1, persisting in many cases up to 4 days post-radiation (Fig. 3). Daily halofuginone treatment suppressed the induction by radiation of TGF-3RII, pSmad3, Smad7, and TSP1 suggesting that the protection observed with respect to radiation-induced soft tissue fibrosis was related to attenuation in TGF- $\beta$ signaling. The most prominent reduction in induced TGF- $\beta$ signaling molecules afforded by halofuginone treatment was with $\mathrm{pSmad} 3$, particularly from $48-96 \mathrm{~h}$ post-radiation. This 
observation is consistent with our earlier observations that Smad3 knock-out mice are resistant to radiation-induced fibrosis (21). Likewise, halofuginone treatment resulted in reduction in both TGF-ßRII and TSP1 levels. To a lesser extent, halofuginone treatment lowered Smad7 levels; however, radiation treatment alone only marginally elevated Smad7 levels.

Collectively, the data presented indicate that halofuginone is an effective protector against radiation-induced leg contraction (fibrosis) and the protection is clearly related to halofuginone attenuating the induction of key members of the TGF- $\beta$ signaling pathway. Of particular interest was the demonstration that radiation induces TSP1 and that halofuginone can inhibit its induction. TSP1 is clearly upstream of the other TGF- 3 signaling molecules evaluated in this study. It has been shown in certain wild-type p53 cells lines that activated p53 can up-regulate TSP1 expression (22). Given that radiation can activate both p53 and TSP1, we are currently investigating whether halofuginone can modulate the p53 pathway. TSP1 might serve as a biomarker for monitoring the efficacy of halofuginone should it be evaluated in a clinical setting for protection against radiation-induced fibrosis. The protection afforded by halofuginone to normal tissues coupled with its lack of protection against radiation-induced tumor regrowth in preclinical studies (15) makes it a worthy candidate for human clinical trials.

\section{Acknowledgements}

This research was supported by the Intramural Research Program, Center for Cancer Research, National Cancer Institute, NIH.

\section{References}

1. Hirota S, Tsujino K, Oshitani T, Hishikawa Y, Takada Y, Kono $\mathrm{M}$ and Abe M: Subcutaneous fibrosis after whole neck irradiation. Int J Radiat Oncol Biol Phys 52: 937-943, 2002.

2. Bartelink H, Horiot JC, Poortmans PM, et al: Impact of a higher radiation dose on local control and survival in breast-conserving therapy of early breast cancer: 10 -year results of the randomized boost versus no boost EORTC 22881-10882 trial. J Clin Oncol 25: 3259-3265, 2007.

3. Davis AM, O'Sullivan B, Turcotte R, et al: Late radiation morbidity following randomization to preoperative versus postoperative radiotherapy in extremity soft tissue sarcoma. Radiother Oncol 75: 48-53, 2005.

4. Barcellos-Hoff MH: Radiation-induced transforming growth factor beta and subsequent extracellular matrix reorganization in murine mammary gland. Cancer Res 53: 3880-3886, 1993.
5. Ehrhart EJ, Segarini P, Tsang ML, Carroll AG and BarcellosHoff MH: Latent transforming growth factor betal activation in situ: quantitative and functional evidence after low-dose gamma-irradiation. FASEB J 11: 991-1002, 1997.

6. Anscher MS, Crocker IR and Jirtle RL: Transforming growth factor-beta 1 expression in irradiated liver. Radiat Res 122: 77-85, 1990.

7. Anscher MS, Kong FM, Murase T and Jirtle RL: Short communication: normal tissue injury after cancer therapy is a local response exacerbated by an endocrine effect of TGF beta. Br J Radiol 68: 331-333, 1995.

8. Andarawewa KL, Paupert J, Pal A and Barcellos-Hoff MH: New rationales for using TGFbeta inhibitors in radiotherapy. Int J Radiat Biol 83: 803-811, 2007.

9. Shi Y and Massague J: Mechanisms of TGF-beta signaling from cell membrane to the nucleus. Cell 113: 685-700, 2003.

10. Rabbani ZN, Anscher MS, Zhang X, Chen L, Samulski TV, Li CY and Vujaskovic Z: Soluble TGFbeta type II receptor gene therapy ameliorates acute radiation-induced pulmonary injury in rats. Int J Radiat Oncol Biol Phys 57: 563-572, 2003.

11. Nishioka A, Ogawa Y, Mima T, et al: Histopathologic amelioration of fibroproliferative change in rat irradiated lung using soluble transforming growth factor-beta (TGF-beta) receptor mediated by adenoviral vector. Int J Radiat Oncol Biol Phys 58: 1235-1241, 2004

12. Anscher MS, Thrasher B, Rabbani Z, Teicher B and Vujaskovic Z: Antitransforming growth factor-beta antibody $1 \mathrm{D} 11$ ameliorates normal tissue damage caused by high-dose radiation. Int J Radiat Oncol Biol Phys 65: 876-881, 2006.

13. Anscher MS, Thrasher B, Zgonjanin L, et al: Small molecular inhibitor of transforming growth factor-beta protects against development of radiation-induced lung injury. Int J Radiat Oncol Biol Phys 71: 829-837, 2008.

14. Pines M: Targeting TGFß signaling to inhibit fibroblast activation as a therapy for fibrosis and cancer: effect of halofuginone. Expert Opin Drug Discov 3: 11-20, 2008.

15. Xavier S, Piek E, Fujii M, et al: Amelioration of radiationinduced fibrosis: inhibition of transforming growth factor-beta signaling by halofuginone. J Biol Chem 279: 15167-15176, 2004.

16. Boukamp P, Petrussevska RT, Breitkreutz D, Hornung J, Markham A and Fusenig NE: Normal keratinization in a spontaneously immortalized aneuploid human keratinocyte cell line. J Cell Biol 106: 761-771, 1988.

17. Stone HB: Leg contracture in mice: an assay of normal tissue response. Int J Radiat Oncol Biol Phys 10: 1053-1061, 1984.

18. Hugo C: The thrombospondin 1-TGF-beta axis in fibrotic renal disease. Nephrol Dial Transplant 18: 1241-1245, 2003.

19. Martin M, Lefaix J and Delanian S: TGF-beta1 and radiation fibrosis: a master switch and a specific therapeutic target? Int J Radiat Oncol Biol Phys 47: 277-290, 2000.

20. Randall K and Coggle JE: Long-term expression of transforming growth factor TGF beta 1 in mouse skin after localized betairradiation. Int J Radiat Biol 70: 351-360, 1996.

21. Flanders KC, Sullivan CD, Fujii M, et al: Mice lacking Smad3 are protected against cutaneous injury induced by ionizing radiation. Am J Pathol 160: 1057-1068, 2002.

22. Ren B, Yee KO, Lawler J and Khosravi-Far R: Regulation of tumor angiogenesis by thrombospondin-1. Biochim Biophys Acta 1765: 178-188, 2006. 